

\section{Avaliando o legado de megaeventos esportivos: uma proposta conceitual e de mensuração}

Assessing the legacy of sporting mega events: a conceptual and measuring proposal

Elisangela Aparecida Machado da Silva ${ }^{1}$

Joaquim José Guilherme de Aragão

Yaeko Yamashita ${ }^{3}$

\footnotetext{
${ }^{1}$ Pesquisadora de pós-doutorado, PPGT-UnB, e-mail: elisangela-machado@hotmail.com Geógrafa, mestre e doutora em transporte, pesquisadora de pós-doutorado - CAPES, na Universidade de Brasília, Brasil.

2 Professor, PhD, FT-UnB, e-mail: aragao@unb.br Engenheiro e mestre em Transportes pela PUC-RJ; doutor pela Universidade de Dortmund, pós-doutorado na University College London e Ecole Nationale de Ponts et Chaussées. Atualmente é professor na UnB e pesquisador do CNPq

${ }^{3}$ Professor, PhD, FT-UnB, e-mail: yaeko@unb.br Engenheira civil, mestre pela Tottori University, doutora em transportes pela University of Wales, pós-doutorado em Nagoya Institute of Technology. Atualmente é professora na UnB e pesquisadora CNPq.
} 


\section{RESUMO}

Este artigo visa apresentar, com base em fontes de pesquisas nacionais e internacionais, os resultados da analise sobre as características dos legados dos megaeventos esportivos sob a ótica do que este fenômeno representa para os organizadores, governos e setor acadêmico. A partir do qual propôs-se um novo paradigma para o conceito de legado de megaeventos, com vistas a definir os elementos que compõem seu objeto e, por fim, apresentar uma proposta metodológica de identificação e mensuração dos legados sobre a perspectiva da Engenharia Territorial, sobretudo para a Copa do Mundo de Futebol de 2014, em Brasília. Por meio deste estudo crítico e conceitual foi possível propor representações para os elementos analíticos do legado e a proposição de um Programas de Consolidação dos Megaeventos Esportivos, que visa fundamentar o planejamento das políticas públicas setoriais em prol da geração e mensuração de legados.

Palavras-chaves: Megaeventos; Legados, Mensuração.

\section{ABSTRAT}

This article aims to present, based on national and international research sources, the results of the analysis on the characteristics of the legacies of the sport mega-events under the optics of what this phenomenon represents for the organizers, governments and academia. From which a new paradigm was proposed for the concept of legacy of mega-events, with a view to defining the elements that make up its object and, finally, to present a methodological proposal for the identification and measurement of legacies on the Territorial Engineering perspective, especially for the 2014 FIFA World Cup in Brasilia, Brazil. Through this critical and conceptual study it was possible to propose representations for the analytical elements of the legacy and the sport megaevents, which aims to inform the planning of sectoral public policies for the generation and measurement of legacies.

Key-words: Mega events; Legacies; Measurement.

\section{CONSIDERAÇÕES INICIAIS}

Popularmente, o termo legado é designado como sendo os benefícios e os malefícios decorrentes do evento (Leopkey, 2013). A preocupação de tornar patente esses efeitos vem sendo uma prática comum quando da realização dos megaeventos mundiais, e sua efetivação vem sendo exigida como uma condicionante para se sediar o evento. Apesar disso, o desenvolvimento de um respectivo campo de estudos é recente, tendo iniciado no final da última década do século passado.

A identificação de legados tem importância estratégica para a venda posterior do seu produto (Copa do Mundo) para outros países, de modo a continuar a expansão do evento, em especial para àqueles em desenvolvimento. Por outro lado, para o país sede, a identificação, a efetivação e a avaliação dos legados visa criar um mecanismo de prestação de contas para a sociedade sobre os recursos financeiros investidos para a realização destes jogos, mostrando assim, que o evento trará efeitos que farão jus aos interesses e às necessidades da sociedade, tais como a geração de impactos positivos na área social, econômica, ambiental, cultural e política.

Afim de caracterizar estes legados buscou-se, por meio de pesquisa em fontes nacionais e internacionais interpretar o significado destes para os organizadores, governos e setor acadêmico. Sendo assim, este artigo visa analisar o conceito de legado de megaeventos esportivos, caracterizar e 
definir os elementos que compõem o objeto e, por fim, apresentar uma proposta metodológica de identificação e mensuração dos legados na mobilidade urbana.

O presente artigo estrutura-se, portanto, da seguinte forma: conceito de legado, a ótica da engenharia territorial, a proposta metodológica de identificação e cálculo dos indicadores e, por fim a analise do legado gerado em Brasília, Brasil.

\section{SOBRE O CONCEITO DE LEGADO}

\section{1. À procura da construção do conceito}

A discussão dos legados surgiu com o aumento dos gastos financeiros na realização dos eventos, na medida em que os investimentos infraestruturais se tornaram cada vez mais dispendiosos; em contraponto a isso, passou-se a exigir que sua exploração, após o evento, se tornasse auto-suficiente (Cashman, 2006; Mangan, 2008; Leopkey, 2013). De fato, há um discurso recorrente em cada megaevento desportivo que ele pode ajudar a transformar uma cidade ou a região de várias maneiras.

Sobretudo as críticas severas aos efeitos negativos sobre as finanças públicas e outras externadas a partir dos jogos realizados em Montreal (Canadá) em 1976, e a mudança em cima da hora das sedes dos jogos em alguns países em desenvolvimento (Colômbia, em 1986), que declararam não ter capacidade financeira ou gerencial de realizá-los, têm aguçado as discussões sobre os legados. No Brasil, entender este conceito e potencializar os efeitos positivos do evento enquanto legado destina-se, sobretudo, a responder às manifestações populares recentes contra a realização da Copa do Mundo de Futebol 2014 e uma tentativa de reabilitar a fama dos jogos, para que outros países continuem a ter interesse em sedia-los.

Nos estudos formulados até o momento (Preuss, 2007; UGF, 2007; ICSSPE, 2008; Brasil, 2008; Macrury, 2008; MacRury e Poynter, 2009; Kaplanidou e Karadakis, 2010; Davis e Thornley, 2010; Cashman e Richmond, 2011; Scassa e Stuart, 2011; Swart et al, 2011; Agha et al, 2012; Swart e Bob, 2012; Marcellino, 2013; Leopkey, 2013) não consta um conceito consolidado sobre o legado dos megaeventos esportivos ou a identificação, avaliação e análise dos legados com coleta de dados sistematizada, dificultando a construção de indicadores específicos capazes de mensurar o legado.

É de se notar que no Brasil compreende-se, salvo poucos desvios, como legado de megaeventos esportivos o conjunto de estruturas e resultados produzidos, direta ou indiretamente, em nível nacional e regional, tangíveis ou intangíveis, planejados ou identificados ao longo do processo, que transformam de forma duradoura a sociedade que os sedia (CGEE, 2013). 
Há de se lembrar que este conceito embarca também opiniões e as atitudes, deveria servir de instrumento para a preparação de uma ação integrada em uma rede de relações vinculadas ao objeto. Os pesquisadores e organizadores que usam o conceito ainda precisam considerar as peculiaridades dos locais de realização dos jogos e o que foi estabelecido como plano de ações nos dossiês e em matrizes de responsabilidade.

O confronto entre demandas teóricas e práticas pode levar a uma primeira inconsistência do conceito, que fica vago e impreciso do ponto de vista teórico e lógico. Por outro lado, as construções teóricas e metodológicas sobre o termo de legado resultam em conceituações abrangentes e de difícil operacionalização para os fins práticos do gerenciamento operacional e econômico dos eventos. Por esta razão, conclui-se que a maioria das pesquisas acadêmicas em eventos esportivos falhou em analisa-los corretamente, confundindo-o aos impactos.

\subsection{Uma proposta de definição pragmática, do ponto de vista de planejamento, gestão e controle}

Por convenção proposta neste artigo, o legado deve estar temporalmente vinculado ao momento do evento e às ações decididas em função do mesmo, cujo conjunto de elementos pode posteriormente sofrer interferência de outros fatos e ocorrências. Mas há de se resguardar a relação de causalidade entre as ações concretas realizadas em função do evento, portanto planejadas e geridas, tais como estabelecidas na matriz de responsabilidade e nos contratos firmados entre os organizadores e país sede.

Há de se ter cautela em incluir e diferenciar legados planejados e não planejados, entendendo por planejados aquelas iniciativas de controle dos atores realizadores do evento e que estão contidos no documento de responsabilidades do evento e no contrato assinado entre os organizadores e o país sede; e os não planejados, aqueles produzidos pela sociedade em geral em virtude da realização do evento, mas que não estão vinculados oficialmente a ele.

Ao revés, defende-se, aqui, que o legado deve referir-se unicamente aos elementos planejados, concretos e de intenção positiva; portanto, não cabe inserir eventuais elementos "intangíveis" ou "negativos", o que não exclui que os efeitos do que foi planejado e executado possam produzir impactos negativos.

Defende-se, aqui, que o conceito deve ajudar aos organizadores, internacionais e nacionais, prospectar o máximo de impactos positivos do evento e, a partir daí, planejar os diversos elementos que possam turbinar positivamente o resultado geral.

Assim, a praticidade para fins de planejamento, gestão e controle devem ser os objetivos prioritários na conceituação pragmática. Nesse sentido, o termo legado deve servir como uma ferramenta lógica que possibilite a identificação e a inclusão de ações e investimentos a serem 
considerados no planejamento do evento, cujos impactos, intencionados como positivos, serão verificados (ou não). Os legados do evento devem englobar, assim, as iniciativas que forem geradas em função da candidatura do país, como momento de partida $\left(t_{0}\right)$, cuja produção é efetivada no momento de escolha do país sede $\left(t_{1}\right)$, cuja finalização está prevista para o fim do evento $\left(t_{2}\right)$.

Dessa discussão pode-se concluir da importância do entendimento dos termos para não confundir legado do evento com impacto do evento e impacto do legado do evento. Assim, essas definições são apresentadas abaixo:

- Os legados do evento são projetos executados em função do evento que constavam do planejamento específico do evento, e projetos executados, que não constam do planejamento específico do mesmo, mas que comprovadamente foram impelidos em função do evento;

- Os impacto dos legados do evento são os efeitos provocados pela realização dos projetos executados em função do evento, e projetos executados que não constam do planejamento específico do evento mas que comprovadamente foram impelidos em função do evento;

- Os impactos do evento são todos os efeitos provocados (decorrentes) pela realização do evento.

Em suma, segundo a proposta aqui formulada, o legado está diretamente relacionado ao planejamento estratégico realizado pelos candidatos à sede dos megaeventos esportivos, com vistas a potencializar num tempo menor e com maior atratividade de recursos financeiros a consolidação de programas que irão contribuir para o desenvolvimento.

\section{ESTENDENDO A CARTEIRA DE LEGADOS: A ÓTICA DA ENGENHARIA TERRITORIAL - CATEGORIAS GERAIS}

Parte-se, aqui, da preocupação de otimizar e agregar valor ao legado enquanto um programa maior, capaz de ativar a implantação das políticas de infraestrutura, inseri-las em um processo mais complexo de projetos que condicionam transformações socioeconômicas, assim como o aperfeiçoamento geral da governança e de seus instrumentos.

Esta compreensão considera o legado dos megaeventos esportivos como ativador do processo de crescimento econômico, desde que inserido no contexto de um programa territorial. Tal programa há de prever uma estrutura de projetos propulsores do crescimento que ajudarão a melhorar o empenho econômico e fiscal do evento.

Desenvolvimento e crescimento são os princípios conceituais que balizam a proposta de concepção do Programa de Consolidação Territorial do Megaevento Esportivo. Colocá-los em prática 
requer a construção e a implementação de um processo econômico que the proveja os meios materiais e social minimamente necessário para a prosperidade econômica sustentada (Aragão et al. 2012). A viabilidade dos projetos se dá pelo resultado econômico das atividades sinergizadas e suportadas por esse território com o objetivo de produzir uma determinada meta de desenvolvimento econômico. Estes projetos são relacionados a estrutura e a superestrutura dos territórios para realização de eventos identificados nos serviços, equipamentos e operação dos sistemas turísticos (Silva, 2014).

Não havendo espaço, aqui, para descrever mais uma vez a abordagem da Engenharia Territorial (Aragão e Yamashita, 2010), ressalte-se a sua utilidade para otimizar a carteira de legados, o planejamento dos megaeventos deve buscar a construção, eficiente e efetiva implantação de um conjunto de projetos necessários à sua realização maximizando a geração de impactos socioeconômicos positivos para a sociedade/localidade sede. Esse conjunto de projetos formaria um Programa de Consolidação do Evento, que promoveria o desenvolvimento/crescimento socioeconômico local.

O legado de um megaevento, concebido e estruturado sob a ótica da Engenharia Territorial, constitui um conjunto de projetos relacionados direta ou indiretamente com a realização do evento, e que produzirão transformações permanentes na sociedade hospedeira e promovem desenvolvimento. Nesse contexto, a mensuração é característica diferencial na abordagem, a partir de indicadores e de uma modelagem específica de avaliação dos legados gerados pelo Programa de Consolidação do Evento Copa 2014.

O Programa de Consolidação do Evento, proposto para estruturação dos legados da Copa do Mundo de Futebol 2014 encontra-se subdivido em quatro grupos de categorias: produtivos, complementares, infraestrutura, catalisadores, tais como estruturado na Figura 1.

Figura 1: Programa de Consolidação do Evento Copa

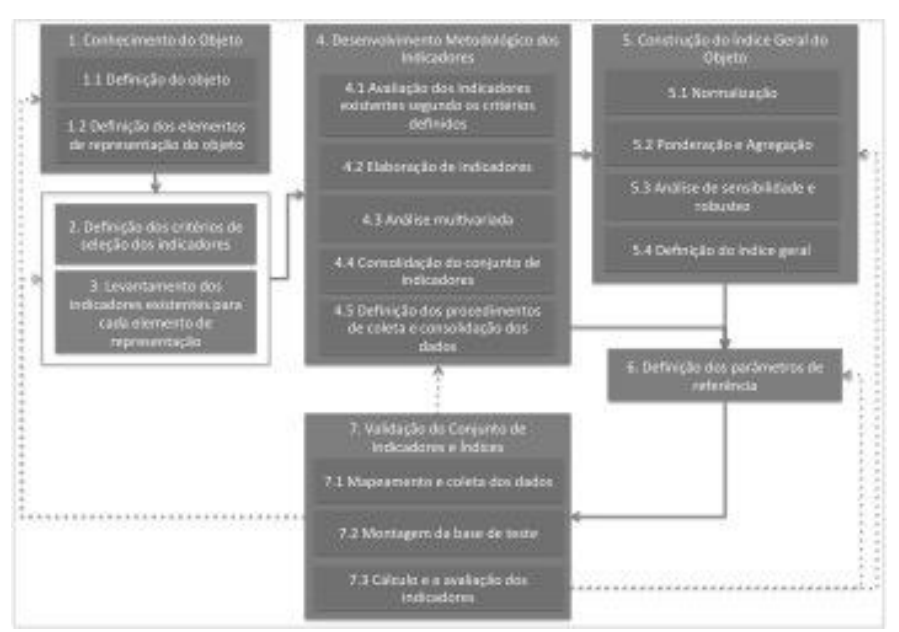

Fonte: Elaborado por Silva, E.A.M., 2014. 
Essa figura explora, da forma mais compreensiva possível, as diversas categorias de projetos e ações que serão demandadas, direta ou indiretamente, por ocasião dos eventos, na medida em que toda a respectiva cadeia de suprimento e comercialização é abrangida (Silva, 2014). Hoje, só parte desses espaços de negócio são considerados no planejamento e no próprio conceito de legado, o que pode implicar em uma subotimização dos efeitos positivos do evento sobre a economia local/regional/nacional.

Ao mesmo tempo, a redução do conceito de legado aos projetos efetivamente colocados em pauta em função do evento permite mais objetivamente medir, o quanto esse potencial é aproveitado no planejamento e realizado na sua execução. Eventos planejados nesse contexto e completando da forma mais extensiva possível o portfólio de projetos previstos serão mais economicamente robustos e politicamente benquistos. A ausência de alguns dos potenciais de projeto, ao revés, pode ser um indicativo da pobreza da concepção do evento.

\section{METODOLOGIA DE IDENTIFICAÇÃO E CÁLCULO DOS INDICADORES DE LEGADO}

Indicadores são parâmetros representativos, condensam informação, possibilitam aproximação a problemas complexos através da simplificação e servem como elementos de difusão de informação (Ceroi, 2004; Royela, 2001; OECD, 2002). A finalidade do estabelecimento de uma metodologia de indicadores e criação de um índice é nivelar o conhecimento sobre o legado, auxiliando na melhor compreensão do que foi produzido em nome deste, bem como sua relação com o processo de crescimento ativados a partir da realização do megaevento.

\subsection{Procedimento de identificação e seleção dos indicadores}

As implicações dessa nova abordagem metodológica são praticas e constituem em uma ferramenta de gestão de legados dos megaeventos com: i) indicadores discutidos e aceitos, sendo resultado de um processo de construção de consenso; ii) custo fixo, ou pouco variável, para o processo de monitoramento; iii) possibilidade de automação de processo, dada a previsibilidade dos processos, bem como do escopo de dados e procedimentos de coleta; iv) reprodutibilidade da experiência, resultante de um processo de padronização de procedimentos e equipamentos; e v) disponibilidade de séries históricas, o que possibilita o acompanhamento do sistema e o amadurecimento do planejamento.

A metodologia proposta tem a implicação de sintetizar os indicadores que representam os elementos da rede de legados, de forma que estes representem o Programa de Consolidação do Evento, ou seja seu potencial de gerar crescimento territorial. E assim concebida, capaz de fornecer a síntese na forma de um índice global, um IGL (Índice Geral de Legado). 
A metodologia de desenvolvimento do sistema de indicadores de legados é composta de sete etapas subdivididas em atividades, conforme ilustrado na Figura 2.

Figura 2: Métodologia para desenvolvimento do sistema de indicadores

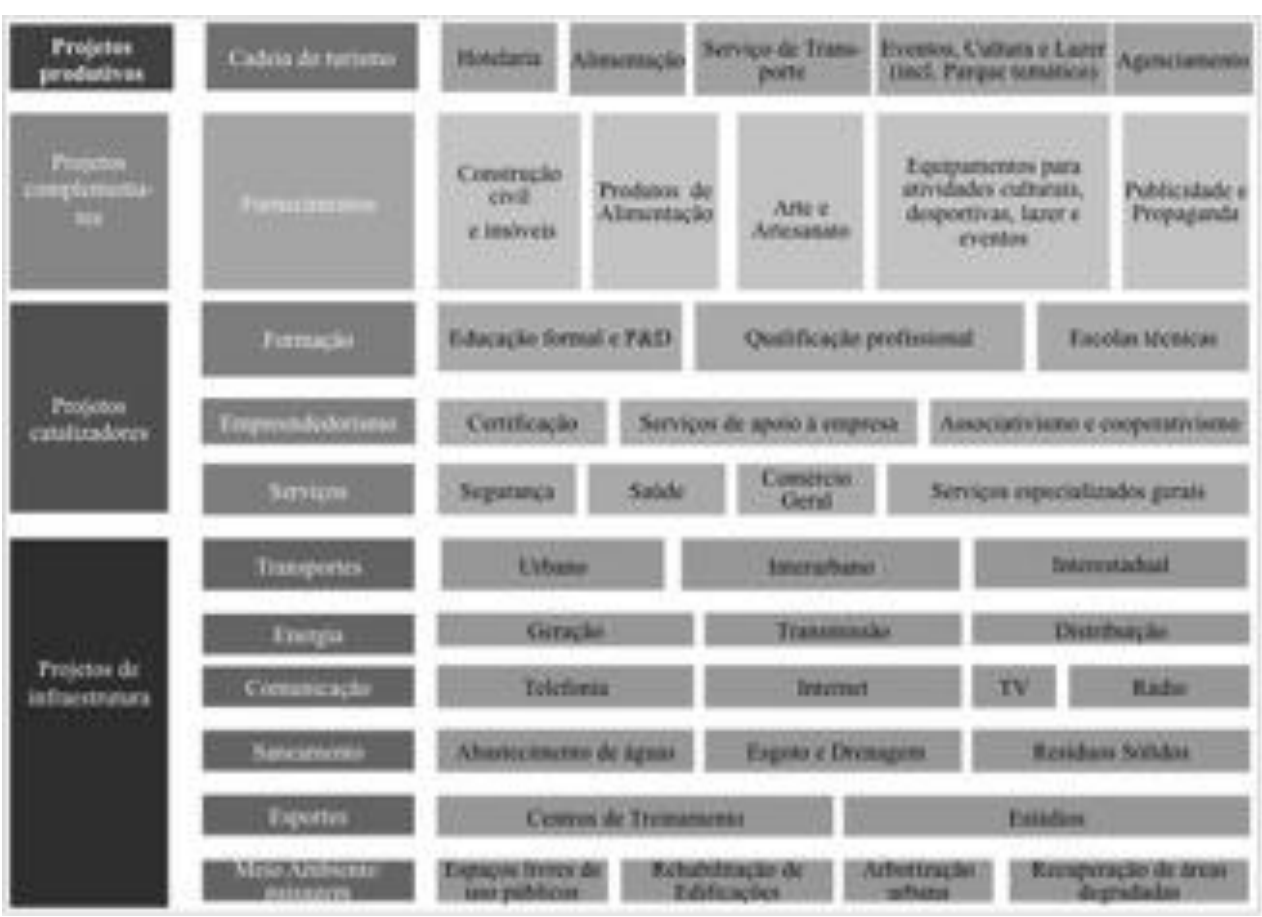

Fonte: Elaborado por Silva, E.A.M., 2014.

A primeira etapa envolve o conhecimento do objeto, tem como objetivo a definição do fenômeno a ser mensurado pelos indicadores e avaliado, bem como seus componentes / elementos de representação.

A definição dos critérios de seleção dos indicadores, segunda etapa, tem como objetivo a definição de critérios de seleção de indicadores que compõem o índice e permite a escolha objetiva dos indicadores componentes do sistema.

Compreende a terceira etapa o levantamento dos indicadores existentes para cada elemento de representação do objeto, procede-se o levantamento dos indicadores existentes que representam cada um dos elementos das categorias do legado (Figura 1).

$\mathrm{Na}$ etapa quatro ocorre o desenvolvimento metodológico dos indicadores com métricas e descrições. Com base nos elementos a serem representados e nos critérios de seleção definidos, procede-se a avaliação dos indicadores existentes levantados na etapa três. Esta avaliação subsidiou a seleção dos indicadores que representaram cada elemento da rede de legados.

$\mathrm{Na}$ etapa cinco, antes de consolidar o conjunto de indicadores, procede-se uma análise multivariada por meio de investigação do grau de correlação entre as variáveis selecionadas, que 
gera uma revisão dos indicadores. Para finalizar a etapa quatro, defini-se os procedimentos de coleta e de consolidação dos dados que alimentam os indicadores.

O objetivo da etapa seis é estudar a estrutura geral do conjunto de dados, avaliar sua conformidade e direcionar as escolhas metodológicas de normalização, ponderação e agregação. Para realizar a sua avaliação é necessário definir os parâmetros de referência que indicam se o estado mensurado é satisfatório ou não, seguindo um padrão de referência ideal.

A validação do conjunto de indicadores e índices, ocorre na etapa sete, uma vez definido o conjunto de indicadores e índices, com suas respectivas métricas e descrições, a proposta é validada por meio de um teste que envolve: o mapeamento e a coleta dos dados; a montagem e alimentação da base de dados; o cálculo e a avaliação dos indicadores. Esta etapa permite identificar e corrigir possíveis falhas e distorções do conjunto de indicadores. E por fim, obter os índices do Programa de Consolidação do Evento Copa 2014.

\subsection{Cálculo do Índice Geral de Legado}

O Índice Geral de Legado (IGL) é obtido da média simples dos índices das categorias do Programa de Consolidação do Evento Copa 2014.

$$
I G L=\underline{I P P+I P C a+|P C+| P \mid}
$$

\section{4}

Em que:

$I G L$ = Índice Geral do Legado

IPP = Índice dos Projetos Produtivos

$I P C a=$ Índice dos Projetos Catalizadores

$I P C=$ Índice dos Projetos Complementares

$I P I=$ Índice dos Projetos de Infraestrutura

A dimensão, ou o legado gerado, é representada por uma escala de "0" a " 1 ". Quanto mais próximo de um, maior é o legado.

Os cálculos dos indicadores mensura a variação do fator entre $\mathbf{t}_{0}$ e $\mathbf{t}_{c}$. $\mathrm{O}$ cálculo do legado gerado com o megaevento, relacionado aos projetos, envolve a coleta do dado para o to e para o tc. Assim, a lógica para composição da expressão métrica do indicador é:

$$
\mathbf{L}=\mathbf{P}_{\mathbf{t} 0}-\mathbf{P}_{\mathbf{t c}}
$$

Em que:

$\mathbf{L}=$ Legado

$\mathbf{P}_{\text {to }}=$ Projeto no momento da candidatura do país sede para o evento

$\mathbf{P}_{\mathrm{tc}}=$ Projeto na realização do evento 
A normalização do indicador (escala de 0 a 1) com base nos valores de referência estabelecidos no momento da candidatura ocorre por:

$\left.\mathrm{IL}=\underline{\underline{\mathbf{P}_{\underline{t} 0}}}-\underline{\mathbf{P}_{\underline{t c}}}\right)$

$\mathbf{P}_{\mathrm{to}}$

Em que:

IL = Indicador do Legado

$\mathbf{P}_{\mathrm{t} 0}=$ Projeto no momento da candidatura do país sede para o evento

$\mathbf{P}_{\mathrm{tc}}=$ Projeto na realização do evento

A análise e julgamento do resultado nos subprojetos é feita ao tomar como referencia a escala de valor ideal (Figura 3), em conformidade aos preceitos da abordagem da Engenharia Territorial.

Figura 3: Exemplo de escala de julgamento e avaliação dos indicadores e índices do legado

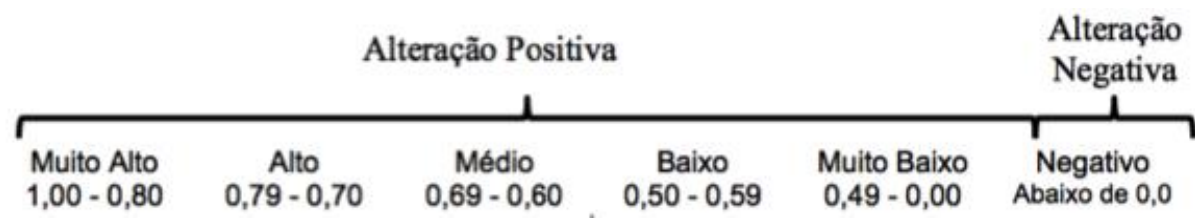

Fonte: Elaborado por Silva, E.A.M., 2014.

Quando os valores mensurados forem superiores ao valor de referência ou negativos; nesses casos os indicadores seriam maiores que 1 ou menores que zero, as razões para este alteração são analisadas e identificados os fatores intervenientes. Com o resultado do cálculo do indicador, a analise é feita considerando um cenário para os legados planejados.

\section{AVALIAÇÃO DO LEGADO DE MEGAEVENTO ESPORTIVO}

No cálculo dos indicadores foram considerados três tipos de legados:

- Planejado - se consta na Matriz de responsabilidade, nos contratos assinados entre o Brasil e a FIFA.

- Potencializado pela ação da Copa - se foi identificada destinação de recursos no Diário Oficial para o projeto, no caso de Brasília a dotação de forçamento foi verificada no diário Oficial do Distrito Federal.

- Não planejado - se não constar em nenhum dos documentos supracitados, mas ocorreu para a Copa. 
A partir das analises, os índices apontados para o legado dos projetos planejados para Brasília, evidenciam um baixo legado ativado pela Copa do Mundo de Futebol 2014 em Brasília (Tabela 1). Mas do que o baixo legado já sabido, demonstra-se a baixa ativação das atividades intensivas na geração de emprego (Projeto Produtivos), de incentivo à qualificação profissional e ao empreendedorismo (Projetos Complementares), ou mesmo dos projetos que melhoram as condições e qualidade de vida da população como é o saneamento básico.

Tabela 1: Brasília (DF) - Índice Geral do Legado Copa do Mundo FIFA 2014 - IGL

\begin{tabular}{|c|c|c|}
\hline Indice & Valor & $\begin{array}{r}\text { Classificação de } \\
\text { Legado }\end{array}$ \\
\hline INDICE GERAL DO LEGADO - IGL & 0,32 & Multo Baixo \\
\hline Indice dos Projetos Produtivos - IPP & 0,15 & Muito Baixo \\
\hline Crescimento do setor de hotelaria & 0,48 & Baixo \\
\hline $\begin{array}{l}\text { Crescimento do setor de agências e operadoras de } \\
\text { turismo }\end{array}$ & 0,44 & Baixo \\
\hline $\begin{array}{l}\text { Crescimento do setor de lazer e entretenimento } \\
\text { Crescimento do setor de bares e restaurantes } \\
\text { Crescimento do setor de serviços de transportes }\end{array}$ & $\begin{array}{r}0,23 \\
-0,39 \\
-0,02\end{array}$ & $\begin{array}{r}\text { Muito Baixo } \\
\text { Legado negativo } \\
\text { Legado negativo }\end{array}$ \\
\hline Indice de Projetos Complementar - IPC & 0,07 & Muito Baixo \\
\hline Profissionais Qualificados & 0,31 & Baixo \\
\hline Capacidade empreendedora & $-0,17$ & Legado negativo \\
\hline $\begin{array}{l}\text { Capacidade de atendimento dos servicos de saúde } \\
\text { Capacidade de atendimento dos servicos de Sequranca }\end{array}$ & - & - \\
\hline pública & - & - \\
\hline Indice dos Projeto Catalizador - IPCC & - & $\cdot$ \\
\hline Crescimento do setor produção de alimentos & - & - \\
\hline Crescimento do setor da construçăo civil e imobiliário & $\cdot$ & - \\
\hline Indice dos Projetos de Infraestrutura - IPI & 0,75 & Alto \\
\hline Capacidade aeroportuária & 1,80 & Muito Alto \\
\hline Crescimento - Duplicaçăo DF-047 (aeroporto) & 0,72 & Alto \\
\hline Rede de telecomunicaçōes & 0,66 & Médio \\
\hline Energia Elétrica & 0,66 & Médio \\
\hline Capacidade do Estádio & 0,65 & Médio \\
\hline Saneamento Básico & 0,04 & Muito Baixo \\
\hline Capacidade da Mobilidade urbana & - & - \\
\hline Qualificaçăo da paisagem urbana & - & - \\
\hline
\end{tabular}

Os Projetos Produtivos, no Programa de Consolidação dos Eventos Esportivos são representados pela cadeia produtiva do turismo e diretamente responsáveis pela ativação dos setores econômicos nos territórios em que estão inseridos. Neste caso, são representados pelos setores de hotelaria, bares e restaurantes, serviços de transportes, lazer e entretenimento, agencias e operadoras de turismo.

A partir da comparação entre a situação do setor do turismo em Brasília antes e depois das intervenções feitas para Copa do Mundo de Futebol 2014. O legado em termos de potencial de faturamento não pôde ser avaliado uma vez que não se contava com informações suficientes sobre a operação da atividade turística. Então, os valores foram mensurados pelo número de estabelecimentos, ou capacidade de atendimento.

Em termos gerais, o índice (IPP) gerado é classificado como baixo (Tabela 1). Os projetos com maior incremento são os relacionados à infraestrutura do setor, como meios de hospedagem, novos 
negócios em agências e operadoras de turismo. Os quais tornam-se capazes de gerar maior impacto sob a economia, a geração de emprego e também nas transformações territoriais, devido a necessidade de mais infraestrutura e serviços necessários à sua operação.

Os demais setores - serviços de transpores, bares e restaurantes, com resultados de baixo impacto, sejam pela mudança de metodologia na coleta de dados, ou pelos fatores do cenário econômico, refletem a adequação do sector ao período de retração de investimentos, evidenciando que nem mesmo a aceleração nos prazos de implantação de projetos e a canalização de investimentos proporcionados por megaeventos como a Copa, foram capazes de acelerar o ritmo de crescimento no turismo.

No resultado, visto por outras perspectivas, a que se considerar os seguintes aspectos:

a. Brasília é uma cidade planejada, com bons e adequados equipamentos turísticos, não se fez necessários, maiores investimentos que culminasse em resultados mais expressivos. Haja visto a boa avaliação conferidas pelos turistas.

b. Brasília é, predominantemente, um destino turístico de negócios e, nos últimos tempos vem se firmando como destino para eventos. No período da Copa, considerado de baixa temporada, toda a infraestrutura turística ficou disponível para este evento.

c. O cenário econômico apresenta um modesto crescimento econômico no setor do turismo em todo o mundo, apesar das dificuldades ainda reinantes devido a crise econômica de 2008. No Brasil, conforme último Boletim do Desempenho Econômico do Turismo (MTur, 2014), cinco dos sete subsetores componentes do turismo apresentaram saldos correspondentes à expansão do faturamento no primeiro trimestre de 2014 (comparativamente a out.-dez./2014), um, de estabilidade e, um de redução dos negócios.

No caso da hotelaria, houve um crescimento considerável na área da hotelaria, com incremento de novas categorias - o cama café. O aumento no número de unidades hoteleiras (UHT) e também do número de leitos contribui para a atração de turistas de eventos e lazer à Brasília. Isso dinamiza as oportunidades de hospedagem, os investimentos e geração de renda.

No setor de agências e operadoras de turismo, no que pese a mudança de metodologia na contagem dos estabelecimentos, há que se identificar a abertura de novos empreendimentos com serviços receptivos diferenciados e inovadores que atraiu turistas e residentes. Ampliou-se a oferta de serviços na área de lazer e entretenimento. Porém, para avaliação mais precisa deste indicador o ideal é fazer a análise da movimentação econômica. 
No que se refere ao crescimento do setor de lazer e entretenimento, o resultado é considerado como muito baixo. Contudo há que se ponderar que a Copa ocorreu em período de férias e de recesso das atividades de negócio em Brasília, período considerado de baixa temporada. Portanto, há um incremento financeiro e, com isso, uma dinamização na atividade proporcionada pelo megaevento.

Os setores que aparecem com crescimento negativo - serviços de transportes, bares e restaurantes, refletem retração diante do cenário econômico nacional e internacional de baixo crescimento econômico. Setores que são tradicionalmente estimulados pela iniciativa privada, e neste caso pouco ativados pelo advento da Copa.

No caso específico do setor de serviços de transportes verificou-se queda no número de veículos disponibilizados para locação, mas em contrapartida há um aumento nos pontos de distribuição, o que subjetivamente eleva a qualidade da prestação do serviço, gera emprego e contribui para o empreendedorismo.

Se o efeito do legado deixado pelo evento Copa do Mundo de Futebol 2014 for avaliado em termos simplesmente do crescimento dos componentes aqui adotados como referência para o setor, os resultados apresentados levam a crer que o evento oportunizou um crescimento no setor acima dos valores naturalmente esperados para o período e deixa como legado uma infraestrutura hotelaria, que se potencializada contribui para atrair mais turistas, gerar novos/mais negócios, renda e emprego, e ainda, para fixar preços mais competitivos aos turistas.

Os legados identificados por meio dos indicadores - Crescimento do setor de hotelaria, Crescimento do setor de bares e restaurantes, Crescimento do setor de serviços de transportes, Crescimento do setor de lazer e entretenimento e Crescimento do setor de agências e operadoras de turismo, são de grande valor, uma vez que demonstram a ativação das atividades do turismo num período de baixa temporada. No entanto, registra-se que o legado gerado é ainda muito tímido, frente ao potencial impacto que o setor representa na economia local e nacional.

Os Projetos Catalizadores não pertencem diretamente às cadeias produtivas dos esportes ou do turismo, mas catalisam e agregam valor ao processo de crescimento geral destes setores e do território em geral, e ativam setores como educação e capacitação, à saúde, segurança a promoção social, empreendedorismo, entre outros.

A Capacidade empreendedora é classificada como legado negativo, embora se valore como positivo em algumas áreas relacionadas diretamente com a Copa, no geral demonstra que o evento não foi ativador do potencial empreendedor no Distrito Federal, o índice IPC, foi classificado como Muito Baixo - apenas 0,07 (Tabela 1). O legado gerado na qualificação profissional ativado pela Copa do Mundo de Futebol 2014 é Baixo (0,31), sobretudo ao considerar o potencial de geração de 
empregos no o setor (representa 2,2\% do total de ocupados, estimados em 92,793 milhões de pelo IPEA, 2011) e a alta rotatividade que demanda sempre mais qualificação. O legado no setor de serviços de saúde e segurança pública não puderam ser avaliados, uma vez que os dados não foram fornecidos pelos órgãos.

Os Projetos Complementares são uma série de projetos de produção de bens ou serviços relacionados aos projetos produtivos, pertencem à respetiva cadeia produtiva, seja no seu lado montante, seja no lado jusante, e são inseridos diretamente no programa, de forma a reforçar a agregação de valor ao território. No caso de Brasília, são projetos complementares a produção e fornecimento de alimentos, construção civil e imobiliária e, ainda, teríamos os serviços e comércio. Mas não tivemos acesso aos dados para calcular essa categoria (Tabela 1).

Os Projetos de Infraestrutura compreendem, conforme a abordagem da Engenharia Territorial, não apenas o transporte e a logística e demais infraestruturas técnicas, promotoras de ganho de produtividade, mas também a otimização da estrutura espacial e da qualidade ambiental como condição de contorno para os efeitos econômicos desejados. Representam grandes investimentos que impactam a sustentabilidade fiscal; possuem forte efeito na estruturação espacial do território; são o foco primeiro de interesse da Matriz de Responsabilidade proposta pelo governo Federal e Distrito Federal.

Os Projetos de Infraestrutura têm a maior classificação quanto ao legado gerado, exceto para o índice de saneamento básico que encontra-se pouco alterado com a realização da Copa (Tabela 1). Destaque para a ampliação do aeroporto que configura como um dos maiores benefícios alcançados, um legado muito alto, classificado como 1,8, cujo o impacto do legado, perdura por mais de uma década, beneficiando o transporte de passageiros e de carga em Brasília.

A análise da média dos legados do projeto de infraestrutura de ampliação altera positivamente a DF-047. A partir de uma escala normalizada, podemos observar que a média de 0,72 indica que a intervenção na DF-047 propiciou uma alteração positiva alta. Além disso, todos os índices individuais dos subindicadores (IL) geram alterações positivas altas e muito altas. Desta forma, a DF047 teve sua capacidade ampliada no trecho da rotatório do aeroporto, tempo de viagem reduzido entre o Aeroporto e o Plano Piloto em horários de pico, e redução de emissão de poluentes no meio ambiente. Tudo isso, traz legados positivos para a dinâmica da cidade de Brasília.

Para a rede de telecomunicações, diversos casos puderam ser simulados, observados por meio de indicadores de qualidade e de desempenho de rede, variando-se a proporção do uso do recurso compartilhado entre as operadoras, assim como o tipo de tráfego de dados usado por cada uma delas. Em termo de legado os resultados encontram-se expressos como médios atingindo a escala de 0,66. Assim, considerando não apenas o tráfego medido durante a copa, como também o 
acréscimo nos pontos de acesso à rede sem fio, espera-se que os indicadores propostos tenham aplicabilidade durante eventuais campanhas de monitoramento em outros eventos de grande porte.

No caso especifico dos projetos relacionados com a infraestrutura da rede elétrica, fossem propostos quatro indicadores que permitem mapear a cobertura da rede de distribuição de energia elétrica nas cidades sede dos jogos. Esses indicadores são: área de cobertura, potência instalada, extensão da rede primária e número de unidades consumidoras atendidas. Os legados deixados pelas adequações à Copa, são de grande valor e qualidade, 0,66 classificado como um legado médio. Tal infraestrutura só seria possível em horizontes futuros, tendo este evento antecipado esse horizonte.

$\mathrm{Na}$ geração do índice de legado gerado pelo Estádio foram utilizados indicadores relacionados à capacidade de espectadores, conformidade às necessidades do espectador, grau de sustentabilidade, uso de novas tecnologias e potencial de faturamento. O legado em termos de potencial de faturamento não pôde ser avaliado uma vez que não se contava com informações suficientes sobre a operação do antigo estádio. Entretanto, o valor do indicador para o novo estádio pode servir como base para realizar estimativas de renda líquida visando a rentabilidade do estádio. O legado da capacidade do estádio é classificado como médio $(0,65)$.

A classificação do índice de saneamento básico obtida a partir de dados sobre a cobertura de abastecimento de água e coleta de esgoto, e ainda gestão dos resíduos sólidos é 0,04 , ou muito baixo, ou seja, nada ativado pela ações de investimento da Copa.

O desempenho, e portanto o legado gerado pelo setor de transporte, na categoria de infraestrutura do Programa de Consolidação do Evento, está diretamente relacionado ao atendimento que o transporte proporciona às expectativas do usuário e aos organizadores do evento. Os elementos que representam o legado do setor de transportes na realização de um evento estão diretamente relacionados à (i) capacidade de atendimento, (ii) qualidade e (iii) tempo. 0 julgamento é feito a partir de um padrão ideal estabelecido como meta da capacidade de atendimento do serviço de transporte. Entretanto, os dados não foram disponibilizados para a presente análise.

A seleção dos indicadores de Meio Ambiente e Paisagem no Distrito Federal foi feita visando uma boa representatividade para a determinação do legado, contudo, esteve sujeita à obtenção limitada de dados junto a órgãos públicos e de pesquisa. Assim como para outras frentes de pesquisa, a métrica de cálculo dos indicadores de meio ambiente e paisagem é diretamente dependente desta disponibilidade de dados.

Os projetos de infraestrutura têm a maior classificação quanto ao legado ativado pela realização da Copa $(0,75)$, exceto para o índice de saneamento básico que encontra-se pouco alterado com a realização da Copa. 
Contudo registra-se que o legado gerado é ainda muito tímido $(0,32)$, frente ao potencial que se atribuiu o evento de ativação da dinâmica econômica local e nacional. Faltou reverter os recursos e investimentos destinados à realização da Copa a benefícios sociais mais duradouros, como no saneamento básico.

\section{AVALIAÇÃO DO SISTEMA DE INDICADORES PARA O LEGADO DE MEGAEVENTOS}

Alguns aspectos do sistema de indicadores elaborado são importantes e devem ser destacados. Primeiramente, evidencia-se que, segundo a proposta conceitual adotada, os indicadores são especificados por programas e projetos que embora essenciais e necessários para promover o desenvolvimento territorial sofrem maior ativação por ocasião do grande evento. Isso é importante para o acompanhamento contínuo da implantação dos programas/projetos e monitoramento dos efeitos gerados.

Verifica-se, ainda, que o sistema de monitoramento desenvolvido, torna-se estável, visto que não varia com a quantidade de programas/projetos existentes. Isso facilita a provisão de recursos para o monitoramento permanente dos indicadores.

A integração do sistema de indicadores propostos ao planejamento de realização do megaevento esportivo permite acompanhar e avaliar a assertividade das soluções, ao possibilitar uma síntese de uma visão geral do legado, o sistema de indicadores fundamenta todo o processo de planejamento e permite a avaliação de todo o processo em termos de resultados finalísticos.

Contudo, não basta que os indicadores representem os elementos da rede de legados do megaevento esportivo, existe a necessidade de serem viáveis operacional e economicamente, mas sobretudo que sejam consagrados no cenário nacional e internacional.

A coleta de dados propostas em fonte secundária implica, sempre no estabelecimento de uma etapa de pesquisa piloto. Uma vez definido o sistema de indicadores e proposto um conjunto de metodologias para as coletas de dados, faz-se necessária uma avaliação in loco dos procedimentos sugeridos para verificar se, na prática, existem dificuldades técnicas e/ou políticas capazes de inviabilizarem os procedimentos.

A metodologia de composição do sistema de indicadores é um processo piloto para o caso dos megaeventos esportivos e que necessita, naturalmente, de amadurecimento, que só será possível com a execução e reavaliação contínua. Considera-se que a presente metodologia representa a base sobre a qual os Programas de Consolidação dos Eventos Esportivos poderão ser definidos e avaliados, em prol da geração de legados. 


\section{CONSIDERAÇÕES FINAIS}

Esta visão geral do objeto e o desenho do sistema de indicadores proposto só se tornou possível por meio da definição conceitual do que é o legado de um megaevento esportivo. Nesse sentido, destaca-se, como a maior contribuição do trabalho, o estudo analítico realizado sobre tema. A partir desse estudo crítico e conceitual foi possível a elaboração Programa de Consolidação do Evento, com os elementos analíticos do legado.

Esse programa é estruturante - não só do sistema de indicadores proposto, mas de todo e qualquer estudo na área -, já que define e organiza os elementos de análise para a identificação e avaliação dos legados dos megaeventos esportivos. Como complemento ao esforço de identificar uma nova abordagem conceitual realizada nessa etapa do processo de identificação e avaliação dos legados, ressalta-se a importância de se definir um Índice Geral de Legados - IGL. Esse índice é importante para a consolidação da visão geral do legado, instrumento essencial para a avaliação dos resultados finalísticos do grande evento enquanto ativador das políticas públicas no país.

Assim, a abordagem feita por meio da Engenharia Territorial constituiu uma resposta aos diversos desafios encontrados no planejamento e na obtenção de legados dos megaeventos esportivos, bem como do desenvolvimento territorial, tanto urbano quanto regional e nacional. Em contraposição às definições ambíguas e até mesmo conflituosas e gerado a canalização de recursos para dotação de infraestruturas desnecessárias para o momento do evento. Contrariamente, a abordagem conceitual e a metodologia proposta agrega as ações setoriais, de forma a detectar relações sinérgicas ativadores de crescimento e de desenvolvimento.

\section{REFERÊNCIAS}

AGHA, N.; FAIRLEY, S.; GIBSON, H. (2012) Considering legacy as a multi-dimensional construct: The legacy of the olympic games. Sport Management Review, v. 15, p. 125 - 139.

ARAGAO, J. J. G. ; YAMASHITA, Y. (2010) Análise da sustentabilidade fiscal de investimentos em infraestruturas de transporte: construção de uma agenda de pesquisa. Brasilia: CEFTRU/UnB (Texto de Discussão).

ARAGÃO, J.J.G.; YAMASHITA, Y.; GULARTE, J.- Introdução à Engenharia Territorial, apostila do Curso de Engenharia Territorial, Brasília, 2012

BRASIL. Legados de Megaeventos Esportivos. Editores: DaCosta, L; Corrêa, D; Rizzuti, E; Villano,B e Miragaya, A. Brasília: Ministério do Esporte, 2008

BULLETIN OF THE INTERNATIONAL COUNCIL OF SPORT SCIENCE AND PHYSICAL EDUCATION (ICSSPE). Feature: "Mega sport events in developing countries". Berlin: ICSSPE, No 53, Maio, 2008. 
CASHMAN, R. (2006). The bitter-sweet awakening: The legacy of the Sydney 2000 Olympic Games. Sydney: Walla Walla Press.

CASHMAN, R., \& Richmond, A. O. (2011) Sydney Olympic park 2000 to 2010: History and legacy. Sydney: Walla Walla Press.

CGEE. Visão estratégica dos legados dos grandes eventos esportivos copa do mundo 2014. Brasília, 2013.

DAVIS, J.; THORNLEY, A. Urban regeneration for the Iondon 2012 olympics: Issues of land acquisition and legacy. City Culture and Society, v. 1, p. $89-98,2010$.

KAPLANIDOU, K.; KARADAKIS, K. Understanding the legacies of a host olympic city: The case of 2010 Vancouver olympic games. Sport Marketing Quarterly, v. 19, p. 110 - 117, 2010.

LEOPKEY, R. The Governance of Olympic Gsames Legacy. Tese (Doutorado) - University of Ottawa, Ottawa, 2013.

MACRURY, I. (2008) Re-thinking the Legacy 2012: the Olympics as commodity and gift. Twenty-First Century Society, 3(3), 297-312.

MACRURY, I. e POYNTER, G. "London" s Olympic Legacy A "Think piece" report, prepared for the OECD and Department of Communities and Local Government." London East Research Institute, 2009.

MANGAN, J. A. (2008) Prologue: Guarantees of global goodwill: Post-Olympic legacies - too many limping white elephants. The International Journal of the History of Sport, 25(14), 18691883.

MARCELLINO, N. C. Legados de megaeventos esportivos. Campinas - SP: papirus, 2013.

PREUSS, $\mathrm{H}$. The conceptualisation and measurement of mega sport event legacies. Journal of Sport and Tourism, v. 12, p. 207 - 227, 2007.

SILVA, E.A.M. (2014) Modelo de avaliação da influência dos sistemas de transportes para o turismo no desenvolvimento territorial. Tese de Doutorado. Departamento de Engenharia Civil e Ambiental, Universidade de Brasília, Brasília, DF.

STUART, S. \& Scassa, T. (2011) Legal Guarantees for Olympic Legacies. Entertainment \& Sports Law Journal. 9(1), June.

SWART, K.; BOB, U. Mega sport event legacies and the 2010 fifa world cup. African Journal for Physical, Health Education, Recreation and Dance, v. 1, p. 1 - 11, 2012.

SWART, K.; BOB, U.; CORNELISSEN, S. Towards redefining the concept of legacy in relation to sport mega-events: Insights from the 2010 fifa world cup. Development Southern Africa, v. 28, 2011.

\section{AGRADECIMENTO}

Ao Ministério dos Esportes em cooperação com o CNPq, pelo financiamento e oportunidade de realização dessa pesquisa, junto a outros dez equipes de pesquisa de universidades brasileiras. Estendo os agradecimentos a todos os pesquisadores e estudantes da UnB que participaram desse estudo. 